\title{
The Physical Study of Vertical Structure of Temperature, Salinity and Density Layer Structure Between Persian Gulf and Oman Sea
}

\author{
Abdoreza Sabet Ahd ${ }^{1}$, Hesameddin Mehrfar ${ }^{2 *}$ and Mina Mohammadi Pasand ${ }^{3}$ \\ ${ }^{1}$ Collage of Basic Science, jahrom Branch, Iran \\ ${ }^{2}$ Department of Physics, University of Ayatollah Ozma Borujerdi, Borujerd, Iran \\ ${ }^{3}$ Department of Marine Physics, Institute of Geophysics University of Tehran, Tehran, Iran
}

*Corresponding author: Hesameddin Mehrfar, Department of Physics, University of Ayatollah Ozma Borujerdi, Borujerd, Iran

\begin{abstract}
Always oceanographers pay attention to layer structure in the sea environment. Creation of layer structures is because of some phenomenons like double diffusion, internal waves, turbulence modular mixing. In this paper with examination of vertical structure of temperature, salinity and density between Persian Gulf and Oman Sea in different seasons, layer structures appear clearly. Also, countors of the same physical parameters show the existence of regular structure which prove internal waves resulting from the Persian Gulf and flow into the Oman Sea. The exchange flow through the Stait of Hormus results from horizontal density gradient between the Persian Gulf and Oman Sea. In winter the density ratio $\left(R_{\rho}\right)$ in this nearshore region is about 0.7 and in offshore region is 0.2. this shows that in this area, double diffusion forms layer structures which have horizontal variations as well as in the vertical. Coastal topography also seems to affect the double diffusion processes and leads to variations of layering in horizontal directions especially between near and offshore regions.
\end{abstract}

Keywords: Layer Structure; Double Diffusion Convection; Termocline; Termohaline; Persian Gulf

\section{Introduction}

Always oceanographers pay attention to layer structures in the sea environment. Creation of layer structures is because of some phenomenon's such as; double diffusion, internal waves, turbulence modular mixing. When salinity and temperature distribution in water column has a upside down effects with regard to density distribution, very interesting structures can be created in water column which is called double diffusion convection. Two types of regimes are existed in this convection:

a) When salinity and warm water stays above cool and fresh water, the finger regime is occurred.

b) Layering regime is occurred when warm and salinity waters stay below cool and fresh water or water column with constant salinity gradient which is heated. In this situation; one layer in coast due to inconsistency in temperature gradient effect will be created and convection is performed. In result, a thin layer is composed. These two regimes are investigated by the aid of line analysis theory by terner (1976). This regime in Persian Gulf is created by facing with south warm and salinity and with North cool and fresh (Figure 1).

Origin and study of double diffusion convection approximately is about four recent decades in oceanography one of variations of free convection, is a situation which in that fluid has gradients with two or three properties and with different molecular diffusion coefficient. When the gradients have an opposite effect on density distribution, the interesting phenomenon are occurred which mostly, can be seen and observed sea environment. Because salinity and warmth, are properties which create this convection in sea, 
often are known as Termohaline convection. These phenomenon in laboratories in salinity solutions with different temperature in laboratories in salinity solutions with different temperature or in melted alloys are occurred and also are known as double diffusion convection. When a fluid has density layering, this fluid has not any movement. For example, when a warm layer water stays above cool water, fluid will be constant and has not any movement and there is no any other mechanism in this situation, which could dominate the floating force. The composition which its diffusion is faster than the other, can ascend and mixing in vertical point will be created. This process is known as double diffusion convection.

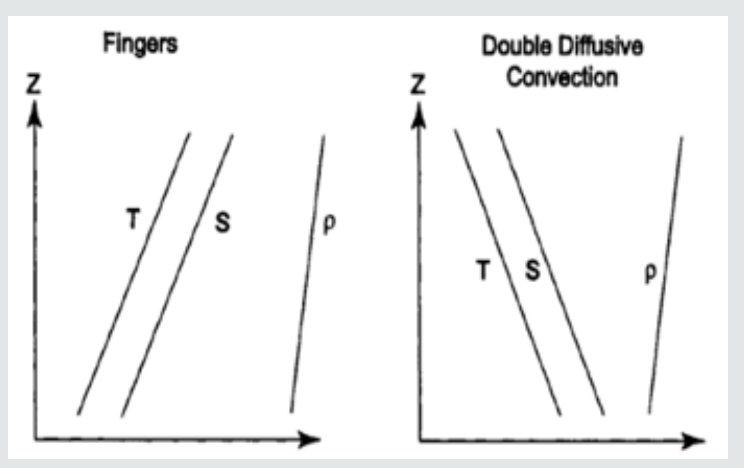

Figure 1: Continual stratification leading in finger regime (left) and double convection (right).

Physical concept of double diffusion process, releasing a part of potential energy by inconsistent vertical gradient. In spite of constant effect on the other vertical gradient is exist. Unlike turbulent mixing and free convection, which cause increasing in potential energy of fluid and wasting of kinetic energy, double diffusion convection cause decreasing in system of potential energy. Thus; coefficient of density diffusion is negative, that is; in allover of density of vertical stratification in increased $[1,2]$.

In ocean environments, due to the difference of salinity and temperature in different depth of waters, double diffusion convection is observed. The occurrence of double diffusion convection is due to three basic factors permanently and naturally in most of oceans and seas:

a. Temperature difference of surface and depth waters.

b. Salinity thickness difference which are exist in these waters.

c. Diffusion difference of warmth and salinity.

\section{The Area to be Studied}

Persian Gulf is a half-closed sea which is located in a low depth region. In this area, the rate of evaporation is extremely greater than the rate of raining and discharges of rivers. Evaporation velocity in Persian Gulf is 200 cmyr- 1 and the fresh water input is about 46 cmyr-1. These numbers show that about $\% 25$ of water substitute by discharge of rivers. This expresses that water exchange with Oman Sea Via Strait of Hormoz, is the main source of water balance for Persian Gulf. The high velocity of evaporation causes that the gulf act as an uprise down estuary with a surface input flow which is more fresher. Circulation and stratification in Persian Gulf seem mainly by three processes: free convection due to evaporation, the exchange of water with Oman Sea and the stimulation of wind. The factors which have effects on water circulation are corilis force, river discharge, coastal topography, and around the coastal line. The effect of coriolis is diverting of surface input flow to the side of coasts of Iran and output flow of undersurface to the side of Arabian coasts [3] (Figure 2).

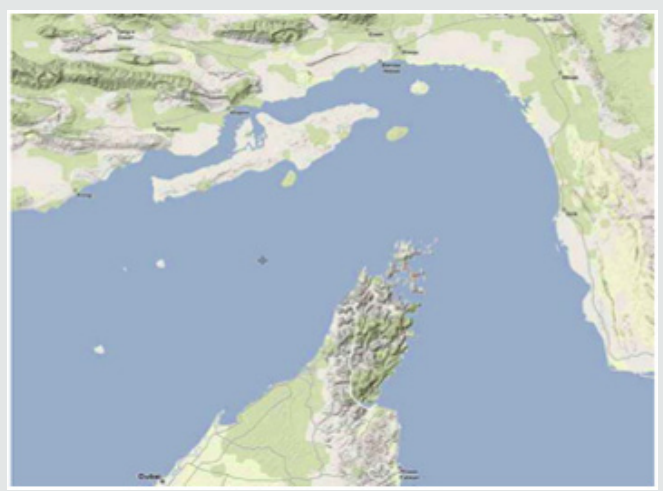

Figure 2: Strait of Hormoz.

According to studies and given numerical models, the input flow of fresh water via Strait of Hormoz due to decreasing the north western winds power, increasing buoyancy forces, increasing south western monsoon and also stratification in Oman Sea, reaches the end of the Persian Gulf. Huge and Hunter (1979) concluded that in their studies that, wind has an active and important role in circulation of Persian Gulf water. Although Hunter suggested that the observed circulation cannot due to the transmition of Akman. Confusion processes due to vertical mixing in Persian Gulf was studied and discussed by Huge and Hunter. The showed that time scope for vertical mixing in water column is 3 days in winter and 17 in summer. Summer can cause increasing the stratification effects which can prevent in mixing of water column.

\section{Inception Conditions of Double Diffusion Convection}

The simplest way; investigation of system between two horizontal edge which in both sides have salinity concentration, temperature stability and line opposite gradients and salinity. If the thickness of layer is d, with this hypothesis that free boundaries of temperature and salinity keep stable, and density distribution with this equation $\rho=\rho_{m}(1-\alpha T+\beta S)$ was determined, $\rho_{m}$ is average density of water column, $\rho$ is density in depth $\mathrm{Z}$, T is temperature, $S$ is salinity, $\alpha$ and $\beta$ are molecular expansion coefficient and density of salinity in stable pressure. Parameters of this problem are: Ra: Reily number, Pr: Prantel number, $R_{\rho}$ : Density ratio and $\tau$ : Diffusion coefficient ratio.

$$
R a_{s}=\frac{R a}{R_{\rho}}, R a=\frac{g a \Delta T d^{3}}{v k_{T}}
$$




$$
R_{\rho}=\frac{\Delta T}{\beta \Delta S}=\frac{\alpha^{\partial T} / \partial z}{\beta^{\partial S} / \partial z}, \tau=\frac{K_{s}}{K_{T}}, \operatorname{Pr}=\frac{v}{K_{T}}
$$

According to second dimensional line constancy analysis and by using Business approximation without friction effect, we can refer to the equations of movement and salinity and temperature diffusion for both composition with similar scopes.

$$
\begin{aligned}
& \left(\frac{1}{\operatorname{Pr}} \frac{\partial}{\partial t}-\nabla^{2}\right) \nabla^{2} \psi=-R a \frac{\partial T}{\partial x}+R a_{s} \frac{\partial S}{\partial x} \\
& \left(\frac{\partial}{\partial t}-\nabla^{2}\right) T=-\frac{\partial \psi}{\partial x} \\
& \left(\frac{\partial}{\partial t}-\tau \nabla^{2}\right) S=-\frac{\partial \psi}{\partial x}
\end{aligned}
$$

With the solution of the above equations and boundary conditions $\left(\left(\psi=\frac{\partial^{2} \psi}{\partial z^{2}}\right)=0, \mathrm{~S}=\mathrm{T}=0\right.$ at $\left.\mathrm{Z}=1,0\right)$ stable and unstable surroundings are obtained according to Figure 3 in two diagrams of Figure 4 for areas of Persian Gulf, constant boundaries of double diffusion convection of finger regime were drawn which similar to it, was reported by others $[4,5]$.

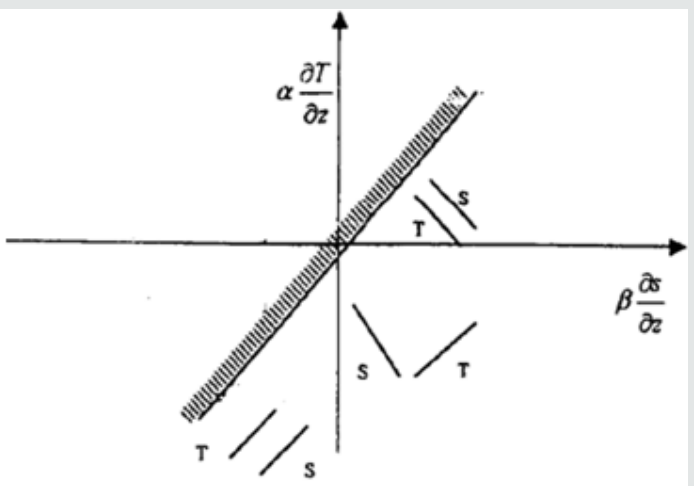

Figure 3: Constant boundaries of double diffusion convection, in North Western of diffusion regime and south eastern of that regime figure.
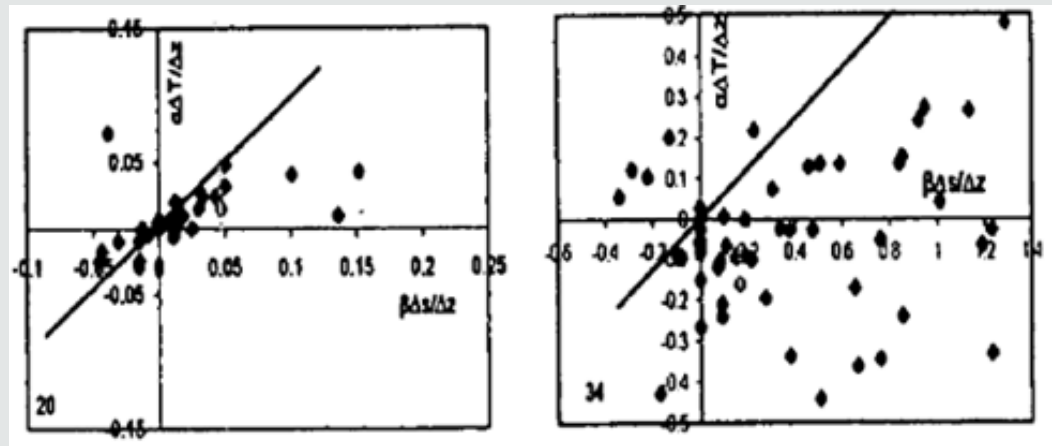

Figure 4: The Raily number diagram of salinity and temperature in Persian Gulf in the stations of 34 \& 20 in winter.

When, $R_{a}<0, R_{S}>0$ are constant gradients and have no any growth. The time when $R_{S}>0, R_{a}<0$, fluid is dynamically inconstant.

Finger regime conditions to density rate is $1 \leq R_{\rho}<10$ and diffusion regime is $0 \leq R_{\rho}<1$. By using this temperature difference running the double diffusion convection and density rate was parameterized by the researchers of heat flux.

Weak diffusion regime $R_{\rho}<0.3$

Average diffusion regime $0.3<R_{\rho}<0.77$

Extreme diffusion regime $0.77<R_{\rho}<1$

$R_{\rho}$ values are greater than 1 , refer to the finger regime actinty and usually limited to the domain of $1<R_{\rho}<7$

Weak finger regime $R_{\rho}>3$

Middle finger regime $1.56<R_{\rho}<3$

Extreme finger regime $1<R_{\rho}<1.56$

Rodik (1983) defined a parameter with the name of Terner angle which indicates the type of double diffusion convection:

$$
T u=\tan ^{-1}\left(\frac{R_{\rho}+1}{R_{\rho}+1}\right)
$$

Thus:

Finger regime (in the most extreme situation in $\mathrm{Tu}=90$ $45^{\circ}<T u<90^{\circ}$

Diffusion regime (in the most extreme situation in $\mathrm{Tu}=90$ $-90^{\circ}<T u<-45^{\circ}$

Double diffusion convection is impossible $-45^{\circ}<T u<45^{\circ}$

For the rest of Tu values, there is static constancy. Robertson and colleagues (1995), according to Terner angle with more details, divided the regimes as flour:

Weak diffusion $-67.5^{\circ}<T u<-45^{\circ}$

Extreme diffusion $-90^{\circ}<T u<-67.5^{\circ}$

Constancy $-45^{\circ}<T u<45^{\circ}$

Weak finger $45^{\circ}<T u<67.5^{\circ}$

Extreme finger $67.5^{\circ}<T u<90^{\circ}$ 


\section{Calculations and Results}

In this research; the analysis of temperature and salinity profiles which are obtained by CTD frameworks during the cruising Mont Michael's ship (1992) was used (Figure 5).

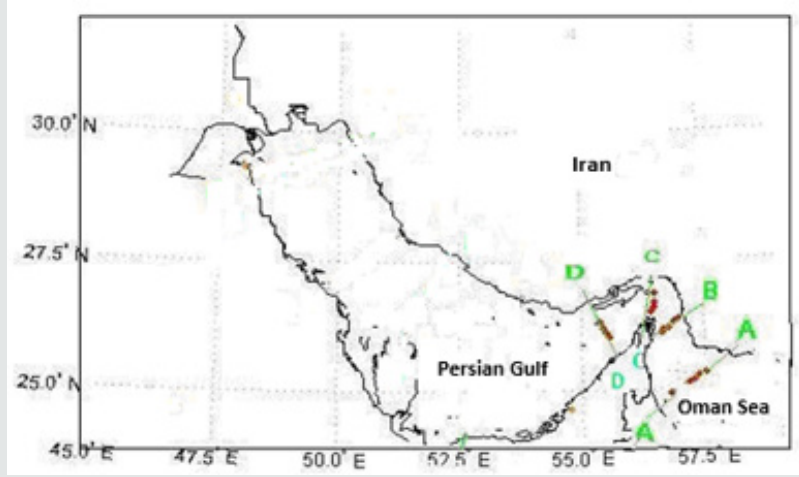

Figure 5: Stations of area to be Studied.

Density ratio $\left(R_{\rho}\right)$, is key parameter in the study of double diffusion convection. Infact, double diffusion convection with density rate for temperature and salinity profiles is calculated by this equation: $R_{\rho}=\frac{\alpha \Delta T}{\beta \Delta S}$

Density ratio (or constant ratio) for $R_{\rho}>1$ is propitious for finger regime, $0<R_{\rho}<1$ is proportions for diffusion regime; $R_{\rho}=0$ is implied for steady temperature, $R_{\rho}<0$ implies for constant gradient for both $\mathrm{S}$ and $\mathrm{T}$. and there is no convection.

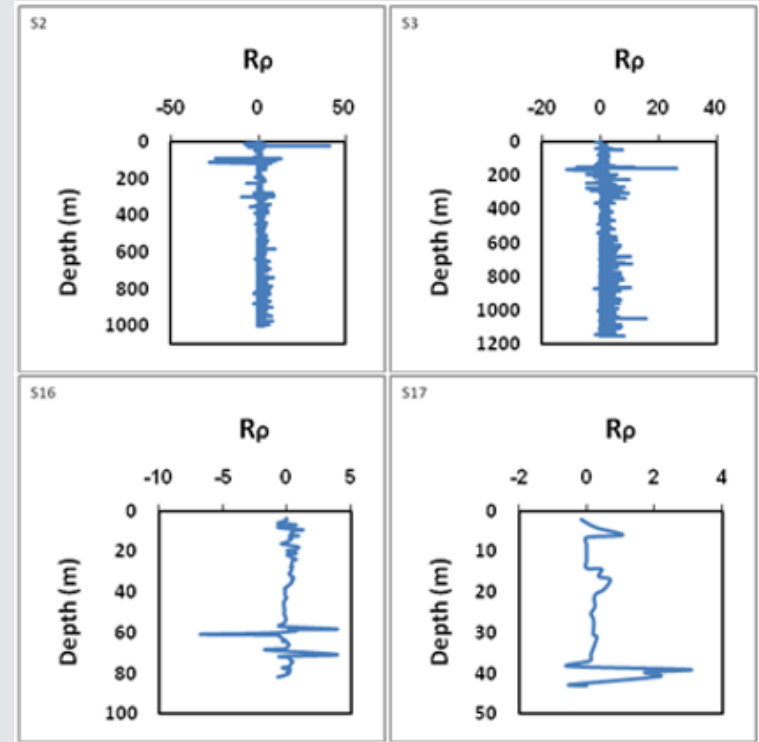

Figure 6: Density ratio profiles $\left(R_{\rho}\right)$ according to depth for a number of stations in winter.

In Figure $6 \& 7$, examples of density rate profiles to depth for the stations to be studied were drawn in two seasons of winter and summer. By using these diagrams, we concentrate on the investigation of process of double diffusion and the type of this convection. By studying the density rate profiles, we can find that in Oman Sea, both processes of double diffusion convection include finger regime and diffusion regime is occurred and has the effective role in transmition of worth and salinity, which upside down temperature in these water can be as a source of worth. In Persian Gulf, the structures of vertical termohalain just in common boundary surface waters with centeric waters, the phenomenon of diffusion regime was confirmed. So, temperature upside down in the boarder of deploy in winter indicates that the behavior of double diffusion convection is the type of diffusion regime. Example of density rate value in coastal areas is about $\% 7$ and in areas which are for away form coast is about \%2. Coastal topography effects or extreme changes of coast can also be effective in creating the double diffusion convection which is the type of diffusion regime.

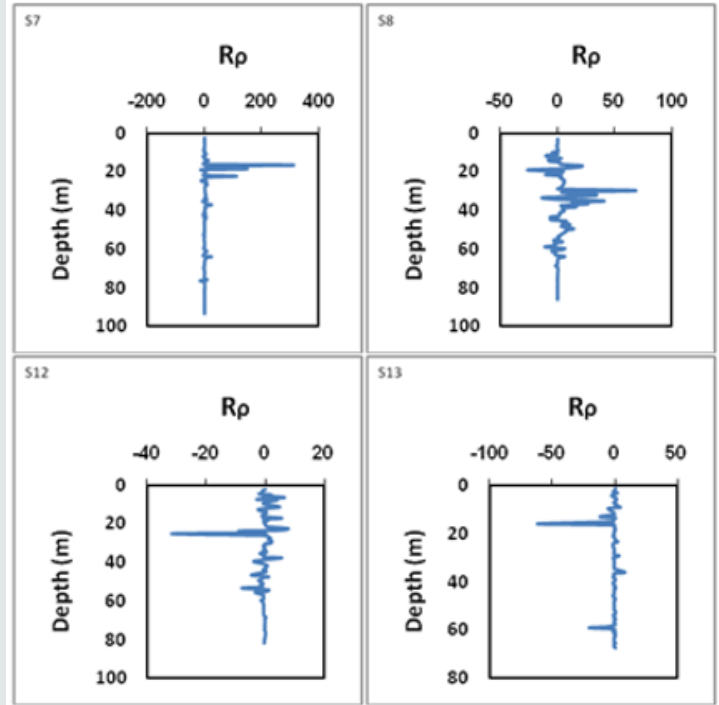

Figure 7: Density ratio profiles $\left(R_{\rho}\right)$ according to depth for a number of stations in summer.

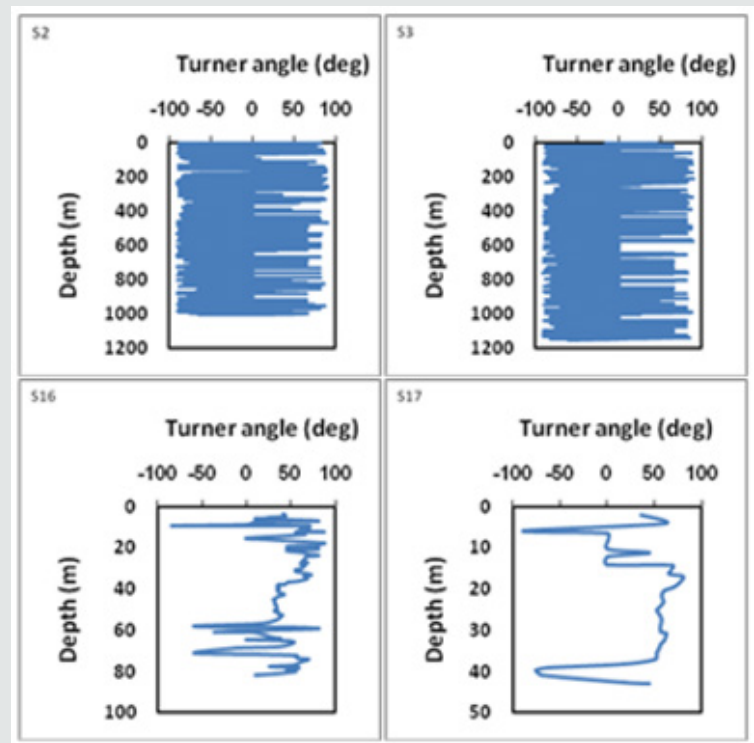

Figure 8: Terner angle profiles $\left(R_{\rho}\right)$ according to depth for a number of stations in winter.

Rodik (1983) defined a parameter by the name of Turner angle which by using this equation, we can recognize the type of 
double diffusion convection. In this way that if $45^{\circ}<T u<90^{\circ}$ is finger regime and when $-90^{\circ}<T u<-45^{\circ}$ is diffusion regime is occurred when $-45^{\circ}<T u<45^{\circ}$, the occurrence of double diffusion is impossible. For the rest of flour values are static constant. In Figure $8 \& 9$, some examples of Turner angle profiles to depth for stations in both winter and summer seasons are drawn. By using of these diagrams, we investigate the double diffusion process and the type of this convection.

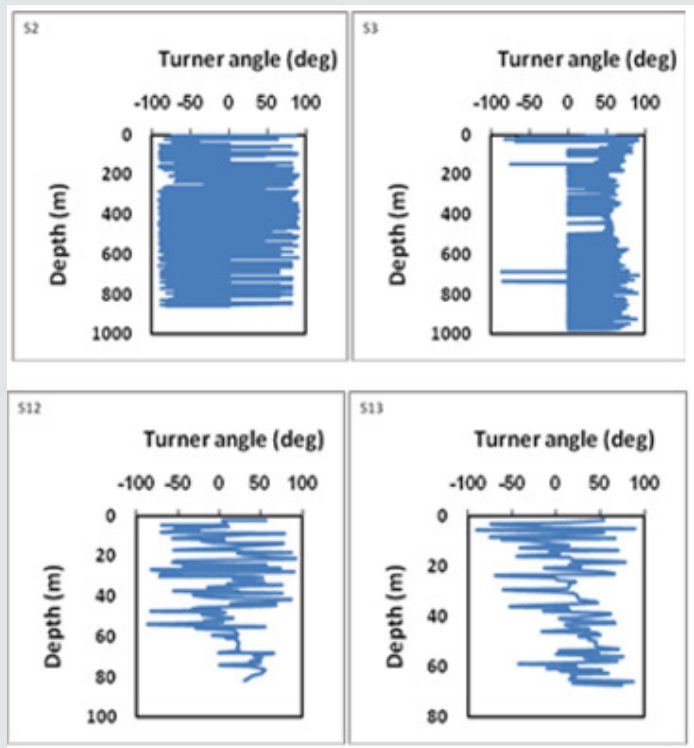

Figure 9: Terner angle profiles $\left(R_{\rho}\right)$ according to depth for a number of stations in summer.
By investigating the Turner angle profiles for stations to be studies, we'll understand that for Oman Sea in summer and winter, double diffusion convection for both kinds of diffusion and finger is observed. But in Persian Gulf, for winter, double diffusion convection, there is the kind of diffusion regime and finger regime is weak. Another important point which has a great importance is half-closed domain of Persian Gulf which causes the increase of the evaporation. And because of this reason, a high-level salinity in this area is created and in result, the heavy salinity waters in depth come in Oman sea and an output floating flow from Persian Gulf is created.

\section{References}

1. Swift SA, Bower AS (2003) Formation and circulation of dense water in the Persian/Arabian Gulf. J Geophic Res 108(1): 4-22.

2. John V, Coles, S, Abozed A (1990) Seasonal cycles of temperature, salinity and water masses of the western Arabian Gulf. Oceanol Acta 13(3): 273281.

3. Azarmsa A, Shafii S, Kamyabi R (1998) Mounth changes of water, level average in Persian Gulf, Oman sea and north of Arabic sea in 1994 Magazine of physics of earth and space, period of 34, 2(1387): 83-96.

4. John WE, Jacobs GA, Kindle JC, Murray SP, Carron M (1999) Arabian Marginal Seas and Gulfs. Univ of Miami RSMAS Technical Report.

5. Kantha LH, Pontius PE, Anantharaj V (1994) Tides in Marginal, semienclosed and coastal seas. Part I: Sea surface height. Univ of Colorado, Colorado Center for Astrodynamics.
(C) This work is licensed under Creative

To Submit Your Article Click Here: Submit Article

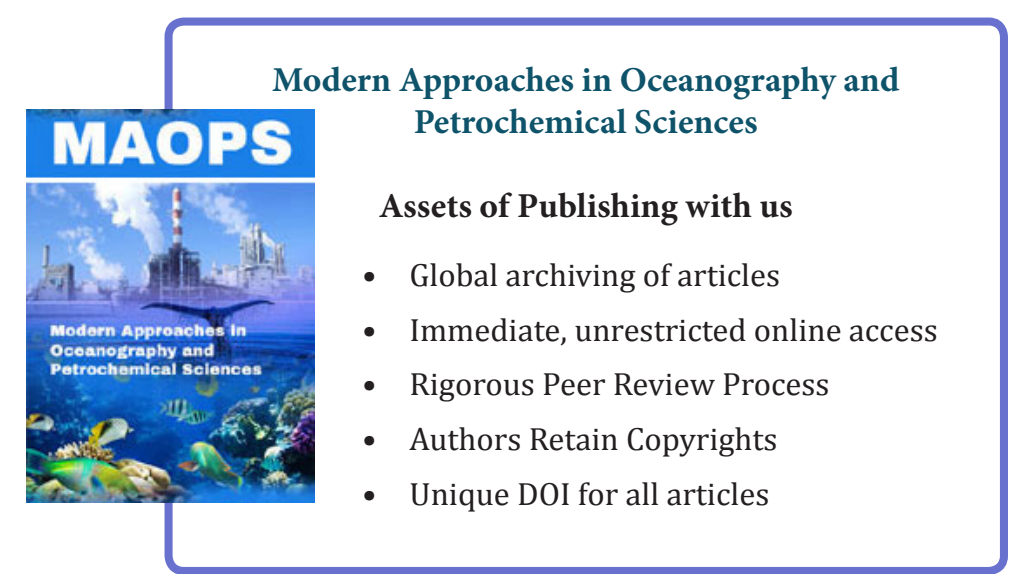

